when it is pointed out that of the 3 cases in 18962 occurred before the month of March, when our record commences.

Since that date but 2 cases of post-scarlatinal diphtheria have occurred among 1,332 scarlet fever patients admitted, in spite of the admission of 150 cases of diphtheria. Of these 2 cases I was isolated on account of rhinorrhœa accompanied by the presence of diphtheria bacilli in the nose. In an adjoining room was a case of diphtheria with scarlet fever. It is possible that the mild attack of faucial diphtheria which supervened six weeks after admission was contracted from this source. On the other hand, the throat may have been infected from the nose. For the second case no cause could be assigned. In neither of them were bacilli found on admission. Both made good recovery.

The first of these two patients was included in a series of 51 cases of post-scarlatinal rhinitis described by Todd, ${ }^{5}$ his observations covering a part of the period included in our report. The leading characteristics of this complaint were as follows: It attacked children only, causing external rhinitis with slight watery discharge. It caused no constitutional disturbances. It was definitely contagious, spreading as rhinitis from child to child, but it did not give rise to faucial or laryngeal diphtheria. A bacillus was isolated by Todd from the noses of these patients, which by all available tests, including that of pathogenicity, was the true diphtheria bacillus, yet he failed in nearly every case to discover any such bacillus in their throats. Were these cases of nasal diphtheria? If so, why did they give rise to rhinitis only and not to faucial diphtheria, and why did not the disease spread beyond the nose? Whatever the explanation, the fact remains that post-scarlatinal faucial diphtheria did not arise. Nevertheless it appears to us that such cases of rhinitis might be the starting-point of faucial diphtheria, and that in future they will require careful supervision.

General Conclusions.

We believe that post-scarlatinal diphtheria is due to the introduction of unrecognised cases of diphtheria into the scarlet fever wards, and that this can only be obviated by systematic bacteriological examinations of all cases on admission, and by separation of those in whose throats diphtheria bacilli are found. If Hoffman's bacillus, which we believe to have no direct causal connection with diphtheria, be sxcluded, the number of such cases, though probably greater among patients more liable to double infection than ours, should not be beyond the isolation resources of most fever hospitals; moreover, absolute isolation does not appear to be essential. At any rate, we consider that the method deserves trial on a larger scale.

Further, we think that some supervision of cases of rhinitis with diphtheria bacilli in the nose should be practised, such as keeping them in bed while the discharge continues; for though these cases do not appear to have given rise at the London - Fever Hospital to faucial or laryngeal diphtheria, yet such an occurrence is quite possible.

REFERENCES

1 Münch. med. Woch., Bd. 42, 1896. 2 Epidem. Soc. Trans., 1896. ${ }^{3}$ Zeit. f. Hyg. und Infections-Krankheiten, Band Xxix

\section{A CASE OF ACUTE TETANUS TREATED BY INTRACEREBRAL INJECTIONS OF} ANTITOXIN : RECOVERY.

By WILLIAM F. GIBB, M.D., C.M., Surgeon to the Paisley Infirmary.

THE following case of acute tetanus was treated with intracerebral injections of antitetanic serum. The patient made a good recovery.

On February 8th, $8899, M$. C., a lad of ${ }_{13}$, while employed at a steam mangle received an injury to his right hand. The four fingers up to the metacarpo-phalangeal joints were severely crushed and burned by passing be rather dirty, was dressed at the Paisley Infirmary Dispensary on the day of the accident and the two following days with boric acid comday of the

He was admitted on February irth into the Paisley Infirmary under the care of Dr. $\mathrm{H}$ C. Donald. The fingers had a yellowish-white appear- ance; they were not painful, and they were devoid of sensibility. He seemed a healthy, well-nourished lad, with no evidence of constitutional seemed a healthy, well-nourished lad, with no evide
disturbance save slight rise of temperature $\left(90.6^{\circ} \mathrm{F}\right.$.).

February $1_{4}$ th. The fingers were still painless, and seemed to be quite dead. The line of separation was well marked. There was some superficial purulent discharge. Temperature $99^{\circ} \mathrm{F}$. The general condition was gond.

February 18th. Amputation of the four fingers at the metacarpophalangeal joints was performed, the heads of the metacarpals being also evening. A drainage tube was passed transversely within the flaps. By hand.

February rgth. - The hand was still painful, swollen, and red. Two stitches were removed, allowing a drachm of pus to escape. The erening temperature was ror. $4^{\circ}$. He was sleepless.

February 2 oth. The remaining stitches were removed. There was much suppuration. The evening temperature was roo. $6^{\circ}$

February 22nd. The back of the hand presented an erysipelatous blush, reaching halfway up to the wrist. There was severe pain shooting up the arm, preventing sleep. The evening temperature was $99.4^{\circ} \mathrm{F}$. He was not so strong as when admitted, but was taking food well. On the 24th he came under the writer's care owing to the absence of Dr. Donald.

February 25 th (seventeenth day aiter the accident). There was constan and severe pain in the hand, and frequently acute shooting pains extending to the shoulder. On the previous night he several times started up and suddenly threw himself back in bed. This morning there was marked stiffness of the lower jaw, and he was unable to separate the teeth more than half an inch. There was no dysphagia. There was slight retraction of the head and opisthotonos, which disappeared during sleep. The whole of the right upper extremity was perfectly rigid, with the forearm semitlexed. This condition was unaltered during sleep. and it may here be added persisted long after the other symptoms. While awake the eyes remained half closed. and the angles of the mouth drawn downwards and outwards. The breathing was rapid (40) and shallow; the pulse was regular, and of good tension, its rate was rco to r20. He took food well The evening temperature was $97^{\circ}$. Chloral was given in doses of ro grains everv four hours.

February 26th. There was no improvement, and he had been excited and noisy during the night. At 2 P.M., ro c.cm. of antitetanic serum (from the Pasteur Institute) were injected under the skin of the abdomen. At
6 P.M., under chloroform. 8 c.cm. serum were injected into each frontal 6 P.M., under chloroform. $8 \mathrm{c} . \mathrm{mm}$. serum were injected into each frontal lobe, $4 \mathrm{c} . \mathrm{cm}$. from the midale fre, and 4 c.cm. above the supraorbital ridge, correspos. For the operation a dental drill and an ordinary antitoxin syringe were used : the wound was closed by collodion without suture. In addition $\mathrm{I}_{4} \mathrm{c}$.cm. were given hypodermically. While on his way to the operating table, the patient had a severe spasm, affecting the neck, back. operating table, the patient had a severe spasm, affecting the neck, back.
and lower limbs. At 9 P.M. he was noisy, and tried to get out of bed. At and lower limbs. At 9 P.M. he was noisy, and tried to get out
ro.3o P.M. ro c.cm. of the serum were given hypodermically.

February 27 th. He had had a restless night. The head was slightl retracted, and the jaw rigid. Respiration was shallow (44), and mainly retracted, and the jaw rigid. Respiration was shallow (44), and
abdominal. At 7.30 P.M. Io c.cm. were injected hypodermically.

February 28 th. He had had a quiet night, but seemed no better. He could only separate his teeth a quarter of an inch. He was troubled with could only separate his teeth a quarter of an inch. He was troubled with
mucous collecting in the mouth and throat. He swallowed milk well.
There was severe spasm of the neck and back. The pulse was feeble (12), and the respirations 48 . The stump was healing slowly.

March Ist, He had a good night, but there was no improvement of the
now tetanic symptoms; the jaw was almost fixed. The thoracic walls were quite rigid, and the respiration was purely abdominal, with a rate of 52 to
6o. The pulse was sott and feeble (II2). He took liquids freely. At 9.3० P.M. ro c.cm. serum were injected into each frontal lobe.

March 2 nd. He was restless and noisy for half the night, and no better in the morning. At 7 P.M. $20 \mathrm{c.cm}$. serum were given hypodermically.

March ${ }_{3}$ rd. The spasms were rather less severe, but the boy was drowsy and weak. The pulse was 116 and feeble ; respirations 68 . There were requent attacks of choking, from tough mucus accumulating in the was given 20 c.cm. of serum hypodermically. The midday temperature was $103.2^{\circ} \mathrm{F}$.

He rested well last night. The jaw was somewhat relaxed but the head continued retracted. He slept almost constantly. The respirations were 68 and the pulse 120 ; the midas temperature was ro3..$^{\circ}$; there was incontinence of urine and

March 5 th. There was severe spasm of the jaw, neck, and back. At 2 P.M. he received $15 \mathrm{c.cm}$. of serum by intracerebral injection. Shortly after he was extremely weak but rallied towards evening. The administration of chloral was stopped at 2 P.M. At 4 P.M. the temperature was 103. $2^{\circ}$, the pulse 128 , and the respirations 68 .

March 6 th. He was restless, excited, and noisy last night; he tried frequently to throw himself out of bed. Chloral was resumed at I A.M. in the same doses. At ro A.M. he was much quieter. The left pupil was widely dilated. and responded sluggishly to light; the right pupil was moderately dilated and responded promptly. He was quite unconscious, and could not be roused by speaking loudly, but by pinching he could be half wakened. While sleeping the lower jaw could be moved passively, but tended to become rigid. Apart from this and the rigidity
of the right arm there was no spasm. At 4 A.M. the temperature was of the right arm there was no spasm. At $4 \mathrm{~A}$

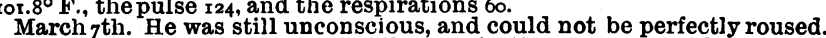
The pulse was 116 , and stronger; the respirations were 52 , and the noon temperature $99.8^{\circ}$. By the afternoon he became conscious, and even

March 8th. He was obviously improving. The temperature was $100.8^{\circ} \mathrm{F}$. the pulse ${ }_{112}$, and the respiration (which was entirely abdominal) 48 ; the pupis were equal. At 6 P.M. a single intracerebral injection was made March ixth. He was much distressed by hawking up tough mucus, which he expelled with great difficulty on account of spasm of the masseters. The chest continued rigid, so that breathing was still chiefly abdominal.
The respiration-rate was 40 , the pulse-rate was $96-$ it was of good tension; 


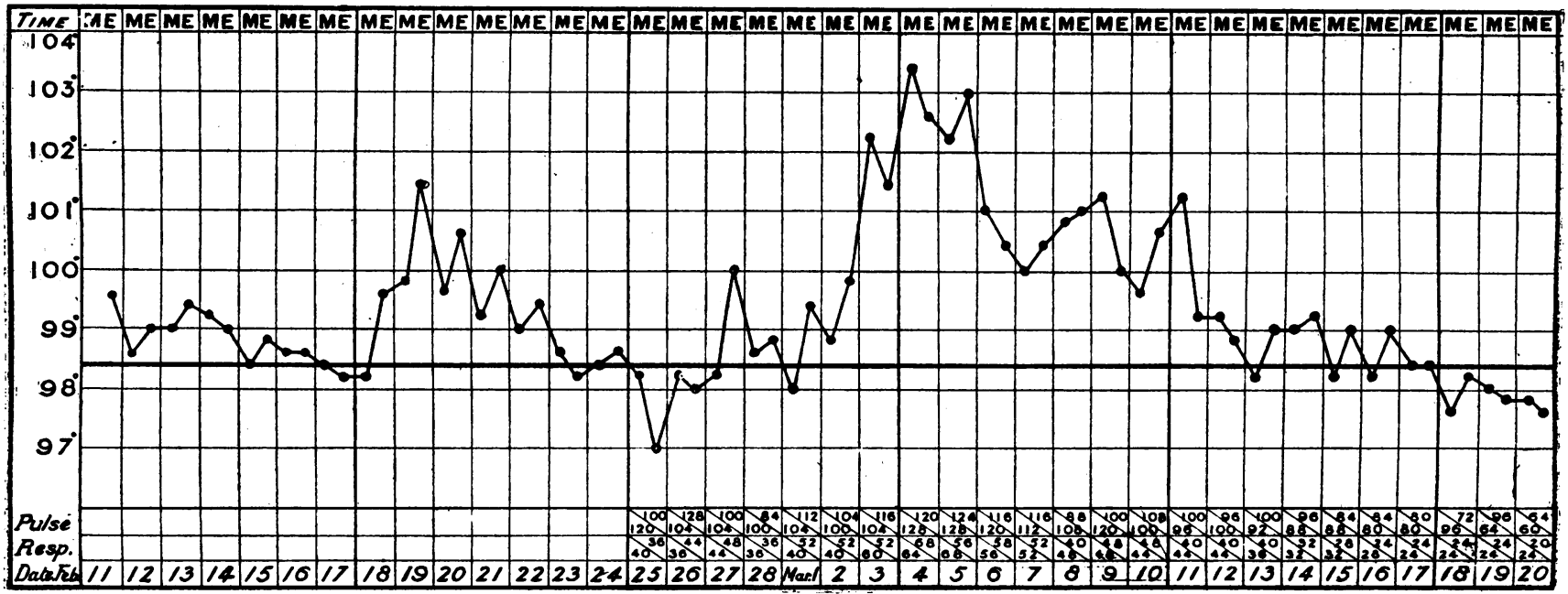

the temperature was ror. $4^{\circ}$. Some dry rales were heard over the front and back of the chest. At noon he had the last injection of ro c.cm., which was given into the right frontal lobe.

March 15 th. All tetanic phenomena had subsided.

April 2nd. The patient was quite convalescent but still extremely thin, weak, and anæmic. He was able to sit up but was not allowed out of bed. There remained some stiffness of the wrist and a small healing ulcer.

\section{REMARKS.}

The treatment of tetanus, as it is at present understood, would appear to aim at the following objects: (1) Maintenance of the patient's strength; (2) controlling, as far as possible, the painful spasms, by chloral ; (3) restraining the development of the toxin in the blood by hypodermic injections of antitoxin; and (4) preventing the toxin from affecting the nerve cells in the higher centres by intracerebral injections of antitoxin. In cases where the presence of bacilli is still suspected, local operation may be necessary. In the case recorded it was presumed that they had been removed by the amputation a week before the first symptom of tetanus occurred.

It is important to bear in mind that immediate improvement is not to be looked for after intracerebral injection. In the case reported by Professor Semple ${ }^{1}$ improvement was delayed Ifor a week, and in the present case for nine days. On March ist and 2nd the patient's condition appeared wellnigh hopeless. The unusually large intracerebral doses of serum were given on account of the intense severity of the symptoms; it is possible, however, that smaller doses might have sufficed. The quantities given were $7 \mathrm{I}$ c.cm. by intracerebral, and $104 \mathrm{c.cm}$. by hypodermic, injection of serum of ordinary strength. Apart from a scarlatiniform rash over the abdomen, lasting three days, the injections produced no ill-effect. There was no sepsis.

To the house surgeons, Drs. Holmes and Watson, thanks are due for their close attention to the case, and for the careful notes they have taken.

1 BRITISH MEDICAL JoURNAL, January 7 th, 1899.

\section{CURE OF MORPHINE, CHLORAL, AND COCAINE} HABITS BY SODIUM BROMIDE.

\section{BY NEIL MACLEOD, M.D.,} Shanghai.

In the British Medical Journal of July ioth, 1897, two pronounced cases of morphine habit were recorded as cured by treatment with bromide of sodium administered, so far as I am aware, in a novel way. Further trial of the treatment there described has met with equally satisfactory results in cases of morphine, chloral, and cocaine habits, and an improved method in the use of the bromide has been adopted, so that large doses of the different drugs were cut off within three days without suffering, and the length of the treatment somewhat curtailed. The cases are recorded in the order of their occurrence.

CASE III.-A Chinaman. aged 32, was educated in America, where he contracted the chloral habit. This habit had lasted four years when his parents brought him to me for treatment. They described him as crazy at times, wandering away from home improperly clad and in all weathers, bemoaned his loss of several lucrative posts in consequence of the habit, andiexpressed their willingness to submit him to any treatment whicl would afford a prospect of removing the craving for chloral. The patient himself, a broken-down looking subject. desired relief, but acknowledged that no reliance could be placed on his promises of assistance towards that end. Circumstances prevented his remaining in the hospital, and I hesitated to undertake the treatment without European nurses in a Chinese house, but his parents, to whom 1 explained that he might injure himself when the effect of the bromide was passing off and that careful nursing would be required, undertook all responsibility, and guaranteed that he would never be left alone. As 1 feared, the mother, who was responsible for the bromide administration. did not give it in the doses and at the times ordered, but I was enabled to determine with certainty that 33 drachms were given between November 9 th and the r3th, during and after which time no other drug was given. He slept continuously from the 13 th to the 21 st, taking about 2 pints of milk daily. During this time no communication with him was possible. Until December xst there were the same feeble motor, mental, and emotional manifestations as described in the first paper, recovery being slower and delusions of fear more marked. When he recovered his power of locomotion, notwithstanding repeated warnings that he was to be watched carefully in reference to stairs, windows, and verandah, there being delusions of persecutions at times, on December roth he succeeded in getting through a window and fell from the first floor, racturing the left tibia and fibula. He was removed to hospital, and the leg was put up in a plaster splint the retured home mained free from it for a year, and for some time has been occupying a mainonibe roll-pid a year

No reliance could be placed on his statements as to the dosage of chloral in twenty-four hours, as he continued to drink from a chloral draught when under iis influence. It was obtained from a Chinese source. Comparing this with the two previously recorded cases, I suspected that the slow development of the bromide sleep was due to the method of administration. This suspicion was confirmed in the next three cases, where the drug was pushed more boldly, with the result expected, and further justified in two other cases to be later referred to, in which the bromide sleep was produced in the treatment of other abnormal states. As will be seen, it was possible for the morphine to be withdrawn more rapidly than in the first two cases.

CASE IV was one of the morphine habit, in a lady: aged 48, whose Family History. - Father died, aged 70 of cerebral hæmorrhage. Mothe living, aged about 70 , subject to migraine. (x) Brother, paroxysma oinomanla, suicide. (2) Brother, alcoholic. (3) Brother, paroxysmal oinomania. (4) Brother, alcoholic. (5) Brother, good health, sound nervous system. (I) Sister died, aged about 4o, of pulmonary tuberculosis after many years suffering from hysterical disorders, anorexia, etc. (2) Sister died, aged about 35, of morbis cordis, consequent on rheumatism ; sound nervous system. (3) Sister living, in good health, was patient herself is the eldest of the family. History of alcoholism in previous generations and collaterals.

Early History. - Shortly after the onset of menstruation she suffered from hysterical cedema of the breasts. She has all her life been subject to periodic illness from neuralgia, in various sites, most often gastric. About twenty years ago was laid up for many months after an injury to
the knee, the long duration of which was probably dependent on neurosis. 